\title{
Immigrant family legal clinic: A case of integrated student supports in a community school context
}

\author{
Marco A. Murillo ${ }^{1}$ (D) $\cdot$ Christine Abagat Liboon ${ }^{2}$ (D) Karen Hunter Quartz $^{2}$ (D)
}

Accepted: 15 October 2021

(c) The Author(s), under exclusive licence to Springer Nature B.V. 2021

\begin{abstract}
Research is growing on the ways K-12 schools can address immigration policy and assist in mediating its impact on students and families. Community schools are poised to address these issues through integrated student supports by taking an asset-based perspective that views community members and organizations as powerful constituents in the struggle for educational equity. We report the findings of a qualitative case study of the implementation of a school-based legal clinic for immigrant families in a high-poverty urban neighborhood. We applied an equity-minded school change framework to examin the range of services offered by the clinic, the process of integrating the clinic's work into the life of the school, and the perspectives of teachers regarding the intersection between immigration and education.
\end{abstract}

Keywords Legal clinic · Immigration education - Immigrant families and children · Community schools · Integrated student supports

\section{Introduction}

Immigration continues to be a highly contentious and debated topic in the United States (U.S.). The Trump administration's attack on immigrants and other vulnerable people exacerbated the need for schools to take an active role in addressing immigration status. For over a decade, both pro- and anti-immigrant policies have sparked undocumented youth to mobilize, advocate, and be visible in the movement to pass immigration reform (Olivas, 2020). Their voices and contributions to the movement have been instrumental in demanding for the humane treatment of all immigrants. Concurrently, there has been a growth in theoretical and empirical research on undocumented youth centered on their lived experience (Gonzales,

Marco A. Murillo

mmurillo2@scu.edu

1 Santa Clara University, 239 Guadalupe Hall, 500 El Camino Real, Santa Clara, CA 95053, USA

2 University of California Los Angeles, Los Angeles, CA, USA 
2016; Suárez-Orozco et al., 2011). More recently, researchers have highlighted the need for educational leaders to address immigration issues within K-12 schools. Given the sensitivity related to immigration status, recent research considers how primary and secondary schools can constructively address this topic (Bhaba, 2019; Gándara \& Ee, 2021; Mangual Figueroa, 2017; Murillo, 2017a; Rogers et al., 2017).

Immigration issues are a catch-22 for many K-12 schools. On the one hand, there are policies in place that prohibit schools from asking families about their immigration status to protect them from discrimination and ensure privacy. On the other hand, there are important reasons to want to address immigration status with families in order to make accommodations and provide services that directly address noncitizen students' needs. As such, supporting immigrant students and families requires careful maneuvering from educators to ensure ethical and appropriate support. As a school reform strategy, community schools have been designed to address educational inequities, partnering with community groups to align and provide integrated supports aimed to improve a wide range of student outcomes (Maier et al., 2017; McLaughlin et al., 2020; Sanders, 2018). Community schools approach learning from a whole-child, whole-family perspective, based on the idea that schools must address students' social, emotional, and academic development (Daniel et al., 2019; Oakes et al., 2017). For this reason, community schools are well positioned to assess and respond to student and family needs related to immigration status. For example, one community school developed sanctuary schooling norms, policies and practices in response to heightened immigration enforcement in the area surrounding the school (Quartz et al., 2021). To study the role of K-12 schools in addressing immigration issues, we designed a qualitative case study of the implementation of a community school-based legal clinic for immigrant families. The following questions guided the study: How is a legal clinic for immigrants developed, implemented, and integrated to operate within a K-12 community school? What are the technical, normative, and political processes involved? In what follows, we review relevant literature and present the study's conceptual equity-minded school change framework that attends to the technical, normative, and political dimensions of community school reform. Our findings highlight the range of services offered by the clinic, the process of integrating the clinic's work into the life of the school, and the perspectives of teachers and staff regarding the intersection between immigration and education. The paper concludes with implications for K-12 educators and leaders to address immigration status issues in schools.

\section{Literature review}

According to Yoshikawa et al. (2016), nearly one million children and youth under the age of 18 are undocumented. Furthermore, approximately 4.5 million children who were U.S.-born and citizens have at least one parent who is unauthorized. Thus, more than 5 million children are at high risk of being directly affected by immigration enforcement policies (Ee \& Gandara, 2020). A growing body of research in child development and psychology has found that unauthorized youth and young adults experience fewer positive outcomes than their authorized peers in education, 
mental health, and financial stability (Yoshikawa et. al., 2016). In addition, stress related to having an unauthorized parent has the potential to negatively impact a child's ability to succeed within the educational system, directly affecting cognitive and educational progress (Ee \& Gandara, 2020). Studies have also shown positive benefits from obtaining an authorized immigration status, including reduced rates in household poverty by 38 percent and reduced rates of maladjustment and anxiety disorders in children of mothers who received DACA status (Amuedo-Dorantes \& Antman, 2016; Duan, 2017; Hainmueller et al., 2017; Lal \& Phillips, 2018). This review is focused on immigrant students and education, touching on the way federal immigration law, state policies, and institutions support and/or hinder the educational experiences and trajectories of undocumented youth and families. The review also includes research on legal partnerships and the role of integrated student supports (ISS) in addressing immigration issues.

\section{A brief overview of federal and state level policy}

Not since the Immigration Reform and Control Act of 1986 has the federal government provided undocumented immigrants a pathway to citizenship. Despite pressure from immigrant rights advocates and undocumented youth to pass immigration reform or relief to undocumented youth, legislative efforts have come to a political standstill (e.g., multiple iterations of the federal Development, Relief and Education for Alien Minors (DREAM) Act). In response to Congressional inaction on immigration and pressure from advocates, President Barack Obama announced Deferred Action for Childhood Arrivals (DACA) in 2012. The program granted qualifying undocumented youth a temporary reprieve from deportation and a work permit, both subject to renewal so long as the program remained in place. Since the start of the program DACA recipients have had greater opportunities to complete higher education and find work in better paying jobs (Gonzales, et al, 2017; Gonzalez et al., 2014). Despite the positive results generated through DACA, the program was rescinded by the Trump Administration in September 2017. After multiple court decisions in favor of DACA, a federal judge ordered the administration to fully restore the program in November 2020. The Department of Homeland Security began accepting applications the following month. However, the program was once again stopped in June 2021.

Undocumented youth have the legal right to a public K-12 education as guaranteed by the Supreme Court's Plyer v. Doe (1982) decision. Per the Court's decision, schools are prohibited from considering immigration status to determine a student's eligibility to enroll (Olivas, 2012). Despite this law, some states have passed policies that require educators to inquire about families' legal status. For example, in 2011, Alabama passed HB 56, an anti-immigrant policy with a provision that required schools to ask and report the immigration status of families. Although a federal appeals court ruled the practice unconstitutional, its passage created a chilling effect (Sheets, 2013). In an attempt to combat these types of discriminatory practices, the U.S Department of Education (2015) released a guide for states and local actors that outlined undocumented students' rights and included ways to support undocumented 
students. Yet, with constant shifts in immigration policy, educators find it difficult to keep pace with up-to-date and accurate information.

\section{Education and undocumented youth}

The Plyler decision gives undocumented students the right to a public education. In some ways, public education shields undocumented students from "illegality." Undocumented youth enter the school system alongside their U.S-born and legally residing peers. They are relatively indistinguishable from other students and not until they approach adulthood do many of them first realize their immigration status may restrict their educational and work opportunities (Gonzales, 2011). Many of them benefit from their parents' community cultural wealth, specifically, tapping into aspirational and emotional intelligence capital that helps students navigate difficult educational settings (Guzmán et al., 2018). While some are determined to overcome the challenges imposed on them by their immigration status and find support, others feel disillusioned and may have restricted access to individuals who can provide guidance (Abrego, 2006; Perez, 2012). Scholars have described this phenomenon as "awakening to a nightmare" (Gonzales \& Chavez, 2012). The layer of complexity immigration status creates for educational and work opportunities makes undocumented students particularly reliant on the support and knowledge of educators.

Undocumented students are likely to come from low-income households, reside in segregated communities, and attend underresourced schools with high student-toteacher ratios (Abrego \& Gonzales, 2010). These educational contexts offer scarce academic opportunities, regardless of legal status, that stratify access to school resources and supports. For example, Gonzales' (2010) life history interviews with 78 undocumented young adults in the Los Angeles metropolitan area illuminated how schools structure opportunity through tracking (Oakes, 2005). In particular, individuals placed in low-ability tracks were less likely to develop positive relationships with educators and receive resources and support to make life decisions. In contrast, participants in high-ability tracks had access to more rigorous curriculum and individualized support that fostered relationships with educators who in some cases facilitated access to the resources they needed to enter postsecondary education.

Relationships with school staff built on trust and support are particularly important for undocumented students. Being undocumented is a stigmatized label that puts individuals at risk. Not surprisingly, undocumented students fear being rejected and ridiculed by educators and peers if they disclose their immigration status, making the decision to do so highly sensitive, contextual, and high-stakes (Mangual Figueroa, 2017; Murillo, 2017a; Perez, 2012). Despite the risks associated with revealing their immigration status, not doing so may limit undocumented students' access to support during the college choice process. Nienhusser (2013) found that schools with a higher number of undocumented students included activities that address their needs during the college choice process. It is important to note that even when undocumented students do ask for help many teachers, counselors, and administrators may lack the knowledge of federal and state policies that support 
undocumented students' college access (Enriquez, 2011). As such, undocumented students often rely on their own networks that tap on the social capital other undocumented students have generated.

Emerging research has examined how school leaders respond to immigration issues. Crawford (2017) chronicled the decisions and actions a school principal in northern California took to protect families when Immigration Customs Enforcement (ICE) settled in the community. The findings demonstrate the need for school leaders to think about protecting students' and families' right to an education when situations related to immigration enforcement arise. They also show the value of building trusting relationships with families and the need to think critically about the way school practices are inclusive of all its members. Doing so may also empower educators to challenge deficit-thinking toward immigrant students and families as well as foster equitable access to resources (Crawford et al., 2018). Yet, as Ee and Gándara (2020) note, immigration enforcement policies are impacting students and families in negative ways, leaving teachers and school leaders to struggle with how to deliver equitable learning and educational opportunities.

\section{School-based immigration legal clinic partnerships and integrated student supports}

Immigration law at its intersection with education may present opportunities and challenges. Research notes that quality representation makes a difference in removal defenses, but many immigrants lack access to legal aid (Jordan, 2016). While there are partnerships between schools and legal clinics that support undocumented students and their families (e.g., Oakland International High School as described in Maier et al., 2017), we know little about the complexities of these partnerships, particularly when the clinic is located on the campus of a K-12 school. There is limited research on the effects of these partnerships. One study on a school-based immigration legal clinic found students perform better academically when they are in a safe and supportive school environment and are not subject to the stress caused by their own or their parents' undocumented status (Lal \& Phillips, 2018). Moreover, an immigration legal clinic located at a school site may help meet a community need for students and families, while also extending legal providers' (i.e., law students) learning opportunities and increasing the number of trained lawyers who practice immigration law (Scharf, 2006).

Emerging research has shown that Integrated Student Supports (ISS) is a promising practice to address disparities in educational outcomes that relate to multiple facets of students' and families' lives (e.g., health, immigration, etc.) (see Oakes et al., 2017). ISS efforts have been traditionally a part of the mission and work of community schools to address academic and non-academic needs. Moore (2014) provides the following definition:

ISS is a school-based approach to promoting students' academic achievement and educational attainment by coordinating a seamless system of wraparound 
supports for the child, the family and schools, to target student's academic and non-academic barriers to learning.

ISS programs are rapidly growing to meet the needs of students and families. Although ISS programs look different across contexts, according to Moore et al. (2017), ISS models typically include five components: (1) needs assessment, (2) coordination of supports for students, (3) integration of supports within schools, (4) community partnerships, and (5) data collection and tracking. These components offer a guide to develop programs and practices that address students' non-academic needs. Moreover, research on community schooling has identified the importance of collaboration between schools and community organizations to ensure that barriers to student achievement-like immigration status-are addressed (Moore et al., 2017). Prior scholarship on community-based services shows the benefits of working together with community organizations, including, for example, medical and legal centers created in urban neighborhoods which have partnered with different professionals and community members (Bliss et al., 2011). Described as medicallegal partnerships (MLP), these professional collaborations provide an opportunity to cultivate relationships to address intersecting problems of practice. These partnerships are also beneficial to both professionals and clients, serving to empower communities and improve delivery of services (Bliss et al., 2011; Carmean, 2012; Weintraub et al., 2010). Recent research captures the role of the MLP model in immigrant serving communities rather than in K-12 schools alone (Fuller et al., 2020; League et al., 2021; Yamanis et al., 2018). Therefore, studying the dimensions of implementing a legal clinic for immigrant families as an integrated student support may provide insight into the ways educational leaders and other professionals can change practice to address immigration issues in $\mathrm{K}-12$ schools.

\section{Conceptual framework}

To understand the integration of legal services on a community school campus we utilize an equity-minded school change framework that considers three dimensions reformers encounter in implementing change: technical, normative, and political (Oakes, 1992). The first dimension, technical, refers to the structures, strategies, and knowledge involved in addressing the reform goals. This dimension tends to be the most straightforward as it involves the arrangement of space, time, and people (structures), governance and curricular practices (strategies), and targeted professional development and learning (knowledge) (Oakes et al., 1993). The second dimension, normative, focuses on the values, beliefs, commitments, and attitudes held by those who are engaged in the reform effort. Norms are deeply rooted in practice and operate in conscious and unconscious ways. Therefore, for educational change to occur there must be a strong commitment and support to engage in reform efforts that deviate from commonplace practices in order to advance equity. The third and final dimension, political, considers the power differentials in reform efforts, inclusive of constituents and resource allocation. It also highlights educational stratification based on characteristics such as race, ethnicity, class, language, and immigration status. Reform efforts aiming to redress disparities in opportunities 
and outcomes are also likely to face resistance that impacts implementation. Altogether, these three dimensions are part of an iterative and mediating change process.

Previous work has applied this framework to examine middle school and detracking reform efforts. For example, Oakes et al. (1997) examined detracking efforts at ten racially and socioeconomically diverse secondary schools, finding that norms about students based on race and class mediated views on intelligence (i.e., racial and cultural explanations for difference in academic outcomes). These norms were perpetuated through school structures (e.g., tracking by perceived ability) while reform efforts to detrack (technical) were met by outcries from influential parents and teachers who drew upon dominant views of merit and engagement (i.e., intelligence) to advocate for the maintenance of current practices (political). More recently, Wiley et al. (2018) applied an equity-minded school change framework to investigate school discipline policies at 33 schools in Denver. Their findings note the use of professional development to increase educators' knowledge of new practices and programs, changes in norms from punishment to prevention, and actions from administrators to reinforce new expectations. These practices were interrelated and intended to support meaningful and sustainable change.

Given the deep connection between immigration and education issues and the complexity in supporting immigrant students and families, an equity-minded school change framework is appropriate for this study. Specifically, an equity-minded framework helps to understand an educational change effort that seeks to develop, implement, and integrate an immigration law clinic on a $\mathrm{K}-12$ community school campus. This work aligns with community school reforms that aim to address in and out of school factors impacting students and families. Maier et al. (2017) highlight four pillars of the community schools reform strategy: (1) integrated student supports, (2) expanded learning time and opportunities, (3) family and community engagement, and (4) collaborative leadership and practice. In this study, we focus on ISS but recognize that all the pillars are linked and mutually reinforcing. We examine the integration of legal supports with a deep appreciation of the connection between schools and the communities they serve (Oakes et al., 2017). We view community members and organizations as powerful constituents in the struggle for educational equity, underscoring the community school pillar of collaborative leadership and practice.

\section{Methodology}

This qualitative case study focuses on the perspectives of school personnel at the community school campus. Case study methodology was utilized to examine the technical, normative, and political processes in the development, implementation, and integration of a legal clinic for immigrant families in a K-12 community school. According to Yin (2018), case study research is an all-encompassing mode of inquiry that focuses on the in-depth study of a phenomenon. In addition, case studies benefit from prior theoretical development and rely on multiple sources of evidence. In this study, the case is the integration of a legal clinic for immigrants located within a K-12 community school. The focus was on the early stages of its 
development and implementation, highlighting the connection between the clinic and the school through the involvement, connection, and knowledge of school and clinic staff. The research questions guiding this study were the following: How is a legal clinic for immigrants developed, implemented, and integrated to operate within a K-12 community school? What are the technical, normative, and political processes involved?

\section{Context}

This study took place at a southwestern urban, K-12 public school in a high immigrant neighborhood in the United States serving approximately 1,000 Latino (83\%), Asian American or Pacific Islander (8\%), Filipino (5\%), African American (3\%), and White (1\%) students. Fifty-one percent of the students are female while $49 \%$ are male. Compared to the school's district and state, a higher number of students were socioeconomically disadvantaged (94\%) and classified as English Learners (28\%) and about two-thirds of the residents in the school's neighborhood are foreign-born, primarily from Mexico, Central America, and Korea. The school's staff consist of 54 full-time teachers, 3 administrators, and many other support staff. Teaching staff identified through self-reported data as Latinx (50\%), Asian American (25\%), African American (3\%), White (19\%), Filipinx (1\%), and two or more races (4\%). Seventy-five percent are female, $25 \%$ are male (2018-2019, Ed-Data). The school is co-located at a complex with five other community schools. Together the six schools serve approximately 4,000 students. The six school principals meet weekly in a collaborative building council to manage and address issues that concern the entire school community, while each community school has its own shared governance council and leadership team that makes decisions about staffing, budget, curriculum, instruction, assessment, and the school schedule. In addition, the school has a longstanding partnership with a local university. As a university-assisted community school, the partnership conducts research and mobilizes resources responsive to the needs of the community.

The school is deeply embedded in the community, partnering with local organizations to address the needs and strengths of students and families. School leaders and teachers recognize the impact of immigration issues on the community. As a result, it developed an asset-based dual language program, supported undocumented students' postsecondary aspirations and decisions, and has declared itself a sanctuary school. School staff have had to adapt to ever changing immigration policies and contexts. For example, in its early years, school staff addressed immigration issues during students' college choice process. After a growth in the number of unaccompanied youth in 2014, the school's principal created a Newcomer course to address these students' needs. The results of the 2016 presidential election necessitated school leaders to address safety concerns when ICE agents were increasingly present in the community.

Amid these changes and the realization that students' and families' needs went beyond the expertise of educators, the school deepened its partnership with the local university to house an immigration clinic on its campus that opened in 
2018. For these reasons, this study examines the early stages of the school-based immigrant family legal clinic. The model of the legal clinic is three-fold: (1) providing legal representation, (2) consultations, and (3) outreach/community education by law clinic staff and law students through presentations and workshops within the school community on legal issues of relevance to immigrant families.

\section{Data instruments}

This case study focuses on the perspectives of school personnel at a community school campus and is informed by multiple data sources, including a survey, interviews, and documents.

Survey An anonymous school staff, 5-7 minute 10-question survey, was administered in December 2019 through a widely-utilized internal school social media platform available to all staff members. The descriptive survey consisted of 8 closed-ended questions, 1 Likert type question on a 5-point scale, and 1 open-ended feedback question. The school staff includes 54 full-time teachers, three administrators, and many support staff, including counselors, office clerks, program specialists, parent representatives, and aides. The survey included questions on: (1) the participant's role and length of time at the school; (2) the school's connection to the legal clinic, and; (3) previous knowledge around immigrant advocacy efforts related to services and communities. A total of 41 staff members responded to the survey, including 29/54 (54\%) teachers, 2/3 (66\%) administrators, 2/3 (66\%) counselors, and $8 / 9(89 \%)$ support staff. Demographic data such as gender and race were not collected from survey participants. A question at the end of the survey redirected staff members to a separate contact form inviting them to participate in a confidential semi-structured interview (see "Appendix 1").

Semi-Structured Interviews Fifteen school staff indicated on the survey they were interested in participating in a 45- to 60-minute interview. From these volunteers, we selected six staff members to represent a range in grade level instruction, years of experience at the school, and administrative responsibilities. The clinic director and clinic fellow were also invited to participate in an interview to provide the clinic's perspective. Race, ethnicity, and gender were not disclosed with the interview team. The eight semi-structured interviews were conducted between January and June 2020 to capture school and legal clinic staff perceptions of the clinic's role on campus. The interviews also asked about the clinic's history and development on a large community school campus. Interviewees included both primary and secondary school teachers whose tenure ranged from the school's inception in 2009 to the beginning of the 2019 school year (see Table 1).

Artifacts/Documents Documents to further inform this study included: protocols related to school and district sanctuary protections; memoranda of understanding (MOUs) and agreements between administrators, the district, and the 
Table 1 Interview participants

\begin{tabular}{lll}
\hline Participant pseudonym & Current role & Length of time at site \\
\hline Abigail & Kindergarten and 1st Grade Teacher & 5 years \\
Elaine & Middle School Science Teacher & 9 Years \\
Olivia & 6th Grade Language Arts & 11 years \\
Yoshua & Middle School and High School Visual Arts & 1 Year \\
& Teacher & \\
Elisabeth & 9 th/10th Grade History Teacher & 8 Years \\
Amanda & Principal & 8 Years \\
Nancy & Clinic Law Fellow & 4 months \\
Ariana & Clinic Director & 2 years \\
\hline
\end{tabular}

university; legal clinic outreach materials and other correspondence such as educational and service flyers.

\section{Data analysis}

Descriptive analyses of survey responses examined the clinic's connection with the school, focusing on whether staff had referred students to the clinic and the type of engagements respondents had with the clinic. Interviews were transcribed and then uploaded alongside documents to Dedoose, a qualitative analysis software platform. The first and second author coded all data. Open coding was first applied to generate a list of codes (Saldaña, 2016). The two authors met to discuss emerging codes and develop a codebook. Seven codes each with sub-codes were developed related to school immigration services, the political context, clinic creation, clinic integration, and participants' connection to immigration issues. For example, the code Clinic Creation/Purpose included the following sub-codes: buy-in/support, space, negotiations, and need. To ensure intercoder reliability both authors coded the same two interviews to discuss the utility of codes and agree on applicability. Focused coding was utilized to identify key elements of the clinic's development, implementation, and integration, which were then informed and arranged conceptually using Oakes' equity minded school change framework (technical, normative, political) to guide the discussion as a process with complex dimensions.

\section{Limitations}

This study is not without limitations. First, the study findings represent the experiences of school and clinic staff and are missing the perspectives of clinic clients and other community members. The initial proposal to conduct the case study included a request to recruit clinic clients and parents to be interviewed. However, the school's research review committee expressed concern that studying clients and parents could undermine their sense of trust and safety in approaching the clinic for a consultation. 
Table 2 Immigrant family legal clinic equity-minded school change

\begin{tabular}{ll}
\hline Dimension & Action/Activity/Event \\
\hline Normative & Proclamation as sanctuary school \\
& Culturally relevant curriculum (e.g., dual language program) \\
& College-going supports for undocumented students \\
& Community-building activities (e.g., advisory board and developing trust) \\
& Developing K-12 and Law school partnership \\
Technical & Space allocation-costs and client protection (privacy) \\
& Professional development on immigration issues \\
& Clinic services-representation, consultation, and community education \\
& Immigration policy changes \\
Political & Immigration enforcement (i.e., deportations) and increased fear \\
& End and restoration of DACA \\
& Competing education interests and limited resources \\
& Students and community advocacy \\
\hline
\end{tabular}

This is a testament to the challenges of conducting research on immigration status in a K-12 school setting, yet also signifies the school's strong commitment to prioritize and protect the privacy of marginalized groups. Second, this is a somewhat idiosyncratic context to study the intersection between legal services and education given the unusual amount of resources (e.g., space, time, connections/relationships, and finances) necessary to locate a legal clinic in a school. Still, examining this connection between legal services and education may provide a lens for advancing a range of legal supports for immigrant-origin students and families.

\section{Positionality}

This research study is the result of more than a decade of partnership and engagement between researchers and practitioners at the school site. Our positionality is deeply rooted in the community. Scholars note the importance of seeking and acknowledging the subjectivities we bring to the research (Peshkin, 1988). These subjectivities may include the choices we make in the research questions we ask, the methodologies we employ, and how we analyze and present data. We also recognize our social identities and connection to immigration issues in the research process as a second-generation Latino male (first author), second-generation Filipino female (second author), and first-generation White Canadian-American female (third author) (for more details see Murillo et al., 2021). To this end, our scholarship in this setting is guided by a commitment to support the wellbeing of the community and research participants (Abrego, 2020). As research practice partners from a local public university, we have collaborated with educators and other leaders to help the school address and solve pressing and relevant issues. Over time the work has included examining immigration issues by considering the way immigration status impacts students' educational experience. As a result, this study is part of an ongoing partnership. 


\section{Findings}

The study findings are presented according to the development, implementation of services, and integration of the immigrant family legal clinic. Across each theme, the study's equity-minded school change framework is applied to highlight dimensions of each action and activity involved with the clinic. Table 2 includes the actions the school and clinic undertook before, during, and after the creation of the partnership to integrate the clinic into the school community. It is important to note that while each activity has been associated with a particular dimension, these activities overlap across dimensions in complex ways that support equity-minded changes in the clinic's integration. For example, the table includes the political context related to immigration policy changes that occured while the school and clinic undertook actions and activities.

\section{Setting the groundwork: developing the clinic}

The development of the clinic began in 2015. In partnership with a local law school, school leaders designed the clinic to extend the school's ability to support community members on immigration issues. As an immigrant-serving community school, immigration issues were prominent in school decisions to support and engage students and families. School norms in and out of classrooms reflected respect for the diversity of its students and community; as Elisabeth, a high school history teacher, noted, "This is a community that is heavily immigrant working class. That's a big part of the identity that all our students share." Given the community's strong immigrant identity, school leaders and staff designed structures and practices that embraced its immigrant roots. For example, the school's dual language program affirmed students' home languages and engaged students in a rigorous, culturally relevant curriculum. Abigail, a kindergarten and first grade teacher, commented on the value of the dual language program, "I think that shows how the school values different cultures and the experiences of different immigrants." In the upper grades, the school's college-going work was mindful of students' immigration status, ensuring students received targeted support and were provided a safe space to disclose their immigration status, if they chose to do so.

A few years after the school's opening, it was clear that immigrant students and families needed support that extended beyond educators' expertise. Teacher interviews demonstrated a growing need to address immigration issues in deep and meaningful ways. Elisabeth shared that while students' and families' fears increased after the 2016 presidential election, these issues had been concerning to community members for years:

So, first under the Obama administration, and then under Trump, immigration enforcement activity tends to create a lot of fear in this community. And really just affect people's life and life possibilities. So, even prior to Trump's election, this was an area of concern. And we had already had students who had family members detained for deportation, even prior to that. 
As a community school, addressing out of class issues in students' lives was important for staff. Many interviewees noted how important it was for them to know and understand out of school factors impacting students' and families' ability to engage. Olivia, a founding lead teacher, succinctly expressed this feeling, "All teachers should have an understanding of the range of issues that affect the families that they work with." For many, membership in a community school required educators to recognize the myriad issues affecting the community. It is within this normative context that the decision to develop an immigration clinic was made.

While the groundwork for the clinic began prior to Donald J. Trump's 2016 election, the need for legal services became more pressing afterwards when the political context became increasingly anti-immigrant. Concurrent with the termination of DACA in 2017 there was an increased presence of Immigration and Customs Enforcements (ICE) agents in the community. According to interviewees many students and families feared coming to school. Olivia shared, "We heard that ICE officers were showing up at school campuses and saying whatever to be allowed into the school campus. So, then we were educated that once you let somebody in, it's too late." Some students shared with school staff they were sometimes late to school because they heard ICE was in the neighborhood. As a result, many school staff participated in training workshops aimed at protecting students and families, some led by student advocates. The school also declared itself as a sanctuary for immigrants, extending the declaration previously made by the district. The preamble to the school's sanctuary school protocol states the following:

We believe it is important to be proactive in protecting and providing resources for our families. Our site, in partnership with community organizations and legal services, will be a refuge where families can seek safety, information, and resources, if they feel threatened or afraid.

Alongside these efforts, school leaders and university partners worked to develop the clinic, which involved maneuvering around a variety of technical and political issues. During the development stage, administrators at the community school's shared campus were faced with competing priorities, as Amanda, the school principal, explained some common concerns from adminstrators:

"Shouldn't we have a space for ESL classes for parents instead of a clinic?" So, balancing out the urgency of [different issues]. Not to deny that [ESL classes] are super important, too. It's something we still want to figure out how to do.

Buy-in from key administrators across the school sites was crucial. Although there was general support among administrators that immigration issues were important, there was hesitancy to allocate space and invest already limited resources to this endeavor. According to Amanda, students and parents across all sites played an important role in the clinic's approval by tying it to the sanctuary schools' protocol: 
There's also an urgency that student voices bring. When they came to present to the Building Council and they said, "We know you guys are considering having a clinic and we're adding that to the protocol. That will be part of the sources we have for families."

Student advocates included the clinic as part of the community's sanctuary school work, which helped convince administrators to vote in favor of the clinic. During her interview, Amanda recalled that once the decision to establish the clinic was settled, finding an appropriate space was an additional challenge. Carefully choosing a suitable location on campus to house the legal clinic along with the expenses associated with renovating spaces to ensure privacy were challenges in the early negotiation. There were technical and bureaucratic hurdles such as complying with the fire code, but most importantly, there was the challenge of strategically selecting a space that was both accessible for community members and also protected their safety and privacy. Ensuring respect for families' safety and privacy was a key normative dimension to the clinic's development.

Amanda reflected on the iterative process of finding a proper space, "We tried a place and the fire department came and said, "you can't have it." In another instance, law school faculty toured a potential space. When they noticed the clinic would be next to campus police, the faculty commented the space would not work. After some additional negotiations that required some programs to move spaces, a room was selected that provided clinic staff the privacy and ability to engage with clients. Some interviewees noted they wished the clinic, as a space, was more visible to students, however, access and privacy issues were mediated by the availability of physical space and competing interests.

The legal clinic was established on the school community campus with robust protocols around sanctuary protections to ensure the safety of students and its members, especially after the heightened anti-immigration rhetoric, deportations, and influx of unaccompanied children. The next step was to implement services responsive to students, families, and the community.

\section{Responding to the community's needs: clinic services}

The clinic's work involves direct individual representation of immigrant students and family members, consultations, and community education. According to clinic director Ariana, the clinic is able to provide this range of technical services with the help of law school students who are enrolled in an experiential learning course at the partner university. Clinic documentation of services indicate that in 2019-20, 26 law students worked alongside lawyers and collaboratively with students, family members, educators, and community organizations. Although the focus is immigration issues, interviews revealed that the clinic has addressed intersecting issues such as employment and tenant rights, guided by the needs of the community and aligned with the clinic's philosophy on community lawyering-collaborative, communitybased approaches to legal services. 
Direct Representation By fall 2020 the clinic had 20 open cases involving 34 individuals. One of the clinic's highest priorities is serving individuals new to the country, with pressing needs as Ariana explains:

The people who have recently arrived in the country tend to be the people who have court hearing dates coming up and filings that if they don't have a lawyer, it's going to make a really major change in their chances. And so, we definitely have prioritized asylum and removal defense for people who come in.

The clinic also provides direct legal representation to secure Special Immigrant Juvenile Status (SIJS) for young people who are classified as individuals that need protection due to abuse, neglect, or abandonment by a parent (USCIS, 2021). Clinic case reports show that since opening, 11 visas were approved with clients waiting for permanent residency. In one example shared by Ariana the clinic provided direct representation to a student who had recently arrived to the country and was undergoing deportation proceedings. The student initially had a lawyer who was charging thousands of dollars. After learning about the clinic, the student scheduled a consultation and learned that he qualified for SIJS. With the clinic's help the student filed for the special visa, pausing deportation proceedings, and allowing him to obtain work authorization. A few weeks later, the client contacted the clinic again to discuss potential worker rights violations. The clinic connected him with a local advocacy group that protects workers and stayed in touch, learning later that the student had joined a local union to advocate for workers' rights-highlighting the range of transformative outcomes associated with receiving legal support.

Although direct legal representation "makes a huge difference," clinic staff noted that cases are extremely time consuming. In addition to ensuring that all the paperwork is filled out correctly, the legal team may accompany clients to court hearings, and assist in any potential follow-up. Because these cases demand a lot of resources, the clinic is limited in its ability to take on all clients. In some instances, they refer clients to local organizations who also provide immigration legal services.

Consultations The clinic also addresses the community's need for information and reputable legal advice. Consultations may lead the clinic to take on a client, refer them to another organization, or provide clarifying information. Nancy, the clinic law fellow, commented on the importance of consultations:

Unfortunately, there is a lot of immigration and notario fraud happening. So, making sure people understand that before you do pay a lawyer, talk to us. One-time consultations aren't only about immigration...some are about workers' rights increasingly now with COVID-19, or virtual consultations have been about unemployment and eviction.

Both Ariana and Nancy indicated that the clinic has provided consultations on a wide range of related issues faced by vulnerable populations, including wage theft, housing evictions, unemployment, and public benefits. Ariana noted that while 
Table 3 Community education

\begin{tabular}{llcc}
\hline Type of Event & $\begin{array}{l}\text { School Year 2019- } \\
2020\end{array}$ & Summer \& Fall 2020 & Total \\
\hline Campus-wide Presentations & 28 & 17 & 45 \\
Campus-wide Outreach \& Meetings & 16 & 6 & 22 \\
\hline
\end{tabular}

tenant services, for example, may not be a core focus of the clinic's in-house legal services, it is important to provide individuals with resources and referrals for where they can get more in-depth legal support. Nancy shared that they have referred clients to organizations that specialize in services beyond the clinic's scope or that already have established support systems. In this way, the legal clinic is building on existing assets in the community, affirming the norms of the collaborative leadership and practice.

Community Education As described in Table 3, the clinic provided a range of community outreach services and presentations between the fall of 2019 and 2020.

A review of clinic documents showed that forty-five campus-wide presentations, twenty-two outreach meetings, and four partnership events took place between Fall 2019 and Fall 2020. These community education efforts focused on a wide range of topics including the Public Charge ${ }^{1}$ rule as well as overlapping issues impacting the immigrant community such as tenants' rights and workers' rights. According to Nancy, the clinic set up a table near the school's main office and entrance in the mornings to answer any questions for students, parents, teachers, and staff. In addition, the legal clinic was invited to present at school events such as "Coffee with the Principal", a monthly meeting for parents conveniently scheduled after they drop off their children in the morning. Amanda shared that the meetings provided parents with important school updates and was treated as a safe space for parents to ask school staff and administrators questions. Events like "Coffee with the Principal" are a blend of both community education efforts and informational sessions where the legal clinic shared details about their services (e.g. direct representation, legal consultations, etc.) and provided updated and relevant information on immigration policy (e.g., Public Charge). After the new year, in 2020, the clinic began their own outreach series of monthly meetings to parents called "Cafecitos con la Clínica" or "Coffee with the Clinic" that covered a variety of topics for immigrant families such as understanding asylum law and tenant's rights. The clinic offered a certificate of participation to parents and an opportunity to join a parent leadership team to those who attended all five parts of the sequence.

\footnotetext{
1 The school administration provided these presentations in response to the January 2020 U.S. Supreme court ruling immigration officials could implement called "public charge." Public Charge is a legal term used for grounds for inadmissibility and a way in which a government official can determine whether a person is likely to become dependent on certain public benefits in the future. The reasons listed could potentially deny a person a green card. The rule went into effect on February 24, 2020 (USCIS, 2020a, 2020b).
} 
In March 2020, the need for legal services was magnified when the school shut down due to the COVID-19 global pandemic. Tenants' rights became even more pressing and, in response to the requests from the community, the legal clinic organized a Zoom Town Hall on housing protections during the COVID-19 pandemic with the help of a local pro-bono legal services organization focused on assisting low-income families. Clinic documents show that between March 2020 and June 2020, the clinic conducted over a dozen presentations over Zoom, with a shift from mostly removal defense cases to fielding questions about "survival emergency mode" related to pandemic benefits and resources. During the summer of 2020, the clinic provided virtual services to families, directing more attention to unemployment and benefits appeals due to the pandemic. They also hosted a webinar called "Knowledge is Power: Immigrant Communities and COVID-19" to overview and address community concerns related to access to services and health care. In fall 2020, the clinic held a presentation about tenants' rights that included certain protections from evictions and actions entitled to county residents (e.g. responding to eviction claims, getting support from a lawyer) as a result of the Coronavirus Aid, Relief, and Economic Security (CARES) Act, an economic relief package signed into law to support families in the United States impacted by the COVID-19 pandemic (CARES Act, 2020).

Prior to COVID-19, capacity to provide services for the entire school and communication across such an expansive community was already a challenge. Nancy shared, "The hard part is capacity." This is an important technical dimension of the change process and underscores the clinic's need to be mindful and strategic about what services to reinforce when the needs of the community extend beyond its capacity.

\section{Integrating the clinic into the life of the school}

The process of integrating clinic services into the life of the school was complex and involved explicit attention to the technical, normative, and political dimensions of change. Despite the school's history of addressing immigration issues, it was important for clinic staff to develop good rapport and relationships across the school and community. Here, we focus on the actions, benefits, and challenges of bridging the clinic's services with the school community. Specifically, we note how the clinic director and law fellow collaborated with school members to build knowledge, refer students and families to the clinic, address community needs, build trust, and partner with community organizations to extend capacity.

Community building occurred through the establishment of an advisory board where open forum meetings were held for the school community. An advisory board of principals and administrators from each school was established to guide and assess the clinic's work. The board meets at least one time per semester to hear about the clinic's work and plans. It also provides feedback on outreach efforts. For example, a meeting agenda from a December 2019 advisory board meeting shows that clinic staff asked attendees to provide feedback on hosting 
a "Cafecito/Coffee" series as well as provide input on professional development topics and discuss organizing a tenant's rights event.

To inform staff about clinic services and provide relevant information on immigration issues, clinic staff attended professional development meetings held at each of the schools. For example, some interviewees shared that after the 2019 changes to Public Charge regulations by the Trump administration there was a lot of confusion about its impact on legally residing and undocumented immigrants. Clinic staff informed the school community of these changes, providing crucial technical knowledge on a complex political issue. Elisabeth appreciated having clinic staff help her understand the nuances of the change:

I don't know how I would understand [the Public Charge issue] if it wasn't for the clinic, because the legalistic nature of it is quite confusing. This isn't just what our kids and families want. This is the law.

Another interviewee noted how clinic staff made themselves available to clarify policies and their impact on families and the community. In contrast, two participants indicated they had yet to learn something substantive on immigration issues from having the legal clinic on campus. This may have been due to having limited exposure as well as being uncertain about how to engage and to follow immigration issues in-depth. Still they were interested in building connections to be better informed and to demonstrate tangible support to the community. Olivia commented that the clinic's presence on the campus signaled a message of support:

I don't have any connections to the legal community. I could have probably tried to do some research, but this just makes it so that it's right [here]. It sends a clear message to our communities that there is advocacy for them

As part of its integration, the clinic also relied on school staff to connect students and families through referrals. According to our survey results, $53 \%(n=21)$ of respondents had referred at least one person. Ariana and Nancy created a onepage referral sheet, which some teachers displayed in their classroom. Three of the six school staff interviewees indicated having referred a student or a parent to the clinic for a consultation. Yoshua, a Visual Arts teacher shared, "I've sent at least two students to the clinic...I've made sure to tell them it's available to them and that any legal advice would be expensive; we're getting it here for free, take advantage of it." For a quarter of survey respondents, the opportunity to refer someone had not come up. However, some interviewees indicated more outreach and information sharing needed to occur for staff, parents, and students. Elaine commented, "I think there are still staff members and definitely parents and students who don't know the legal clinic exists or what the process is to actually get out there. I don't know if that's the thing that takes time." Some suggestions for improving awareness and contact included increasing visibility, distributing business cards, and having flexible walk-in hours.

Interviewees who referred individuals to the clinic noted some of the challenges. For example, Elisabeth mentioned how students, particularly those in the early high school years, were still developing their agency in managing these 
issues: "My $9^{\text {th }}$ and $10^{\text {th }}$ graders... just don't tend to feel the same agency and [they don't say], 'my family needs this... I'm going to go visit the clinic because I know this is something my family needs." Similarly, Amanda mentioned how difficult it might be for some students to trust the legal system after having had negative experiences with lawyers. In addition, despite the school building good rapport and trust with families, it did not automatically "transfer or include" the clinic yet.

An initial challenge for the clinic was developing its own relationships with students and families as a means to build a client base. Amanda noted that some families were hesitant to visit the clinic because their status was "complicated" and they had been advised by other legal experts not to do anything. In other cases, some students feared the stigma of their undocumented status being publicly known. Amanda commented:

I think even with students it happens where people don't want to out themselves...

So I think there's some of that, too. One of our students was very adamant about "don't tell anybody, I'm going there. Don't tell anybody that they're helping me.

Don't ever mention it."

As a result, clinic staff had to be diligent and strategic about building relationships. As the law fellow, Nancy spent time making connections with people through outreach and engagement, giving the clinic a face, and leveraging existing relationships. She shared, "A lot of that involved getting good relationships with the teachers and staff and paraprofessionals who already have the trust from the community and the families." In addition, clinic staff ensure clients that all information will remain confidential.

Key to the development of trust and clinic integration was responsiveness to changing community needs. The clinic's presence made access to accurate information and support available to staff and community members. This was a unique benefit of the clinic, as Nancy explained: "That's what I like about the clinic, we can be responsive to the need." As noted in the previous section, the clinic pivoted quickly to provide supports during the COVID-19 pandemic. Partnerships between the legal clinic and community organizations also helped build relationships that instilled confidence with school staff, especially, students, parents, and community members. According to Ariana, the clinic partnered with organizations to expand its reach and leverage community resources. In addition to referring clients to other organizations for legal support, they plan to build a legal support network across the community. For example, prior to the pandemic, the clinic had planned a roundtable with legal aid providers from the region to meet and connect with a medical expert who runs an interdisciplinary clinic for immigrants in New York. The event had to be cancelled, but Ariana hoped that in making these types of connections across the region in the future they could better serve the population. Elaine appreciated these types of community-building efforts, she shared, "I also like the way that the legal clinic has built alliances with other community organizations. And I hope that stuff continues to deepen."

According to Nancy and Ariana, one of the clinic's goals is to empower clients and the community by increasing a path to citizenship and increasing knowledge to support individual's agency to mobilize. Ariana shared, "The idea would be that we'd be a source of information, and that we'd also, through that information, be 
getting people engaged with trying to work towards change." Overall, she hoped that by building individuals' knowledge they could empower clients and the community during particularly difficult times.

\section{Discussion and implications}

In an era of increased anti-immigration policies and xenophobia, schools have the potential to be safe havens for immigrant students and families. Community schools are poised to address immigration issues through integrated student supports and equity-minded approaches (Malone, 2020; Oakes et al., 2017). Yet educational leaders feel limited in their ability to address immigration in K-12 school settings (Ee \& Gandara, 2020). This paper examines the development, implementation, and integration of an immigrant family legal clinic in a K-12 community school context, framing this change as a process that has technical, normative, and political dimensions.

Events occurring in the larger political context and over time, such as rising cases in deportation, the end and restoration of DACA, and ongoing changes in immigration policy, impacted the local community and made urgent and clear the need for such a critical legal support network on the school campus. However, the clinic's development also required educational leaders to address both technical and political issues as they secured a space for the clinic and balanced competing educational interests. Although some administrators at the co-located schools were initially hesitant, student advocates pressed for the clinic's approval. Drawing on the schools' sanctuary school proclamation, the students argued that a clinic would align with the community's norms and protocols for serving and protecting immigrants. Despite general support for immigrants, committing resources and space for the clinic took time and advocacy. In part, school leaders had to grapple with decisions about what services to prioritize. Previous research has noted the difficult decisions educational leaders make when deciding how to best support immigrant students and families (Crawford, 2017). Amid school reform and accountability efforts targeting traditionally marginalized students (e.g., English learners) and focusing on traditional outcomes (e.g., grades, reclassification, and graduation), the clinic's development raised normative questions about how to best serve students. While the establishment of a legal clinic in a K-12 community school may be unique, its development raises important questions for educational leaders interested in addressing immigration issues.

The implementation of legal services included direct representation, consultations, and community education that provided students and families access to technical information and specialized resources educators could otherwise not provide. In some schools, conversations about immigration status tend to happen during college talk (Murillo, 2017b; Nienhusser, 2013). The clinic's presence allowed the school to extend its support for undocumented students beyond college-going. Specifically, we identified a range of needed services, including workers' rights, tenants' rights, and public benefits, that extended beyond the clinic's core focus on consultation for visas and legal representation for deportation hearings. The clinic was also responsive to 
immediate and pressing changes such as changes to public regulations, and more recently, the COVID-19 pandemic. This extension of legal services was responsive to political and social changes and underscores the importance of assessing and addressing local needs in particular community school contexts. As a whole-child, whole-community reform strategy, implementing social services in community schools is not a one-size-fits-all change process.

The normative dimensions of change were most prominent in the clinic's integration into the school culture and co-located campus. Through intentional trust building efforts and establishing protocols, we learned that the process of integrating legal services into the school was complex and required extensive engagement with the school community. Clinic staff leveraged the school's strong commitment to serving the needs of immigrant students alongside teachers and school staff to help initiate interactions between clients and the clinic. However, trust is not established simply by locating student supports and programs on a school site. The legal clinic continues to build trust as it provides responsive support to the needs of its community members in the midst of COVID-19 and an ever-changing climate. This work is similar to the processes educational leaders must undertake to develop meaningful relationships with students and families, particularly those who are traditionally marginalized by the educational system (Rodriguez et al., 2020). Attending to the normative dimensions of integrating legal services requires understanding how marginalized students and families view and have experienced the legal system. Acknowledging the fear, intimidation, and nightmare scenarios so many have experienced is an important starting point in developing a foundation for thoughtful and respectful collaboration. We learned that even in a school community with a deep-rooted sense of trust and safety, integrating legal services requires ongoing trust and relationship building.

Our findings provide insight into the first four components of effective integrated student supports (ISS): (1) needs assessment, (2) coordination of supports for students, (3) integration of supports within schools, and (4) community partnerships. The fifth component, data collection and tracking, with a particular focus on student outcomes, is also crucial. As the recent National Academy (2019) report, Monitoring Educational Equity, suggests, measures of educational equity must capture the contextual factors that affect learning, such as access to ISS that address adverse childhood experiences, housing insecurity, poverty, and other issues. Research has focused on the relationship between ISS and student performance outcomes. For example, evaluation findings from the Wraparound Zones (WAZ) initiative in Massachusetts showed that students in WAZ schools performed better in English Language Arts and math assessments than students in non-WAZ schools (Gandhi et al., 2016). In addition, a review of 19 evaluation studies found positive outcomes associated with ISS in areas such as attendance, grades, and graduation (Moore et al., 2017).

Connecting the delivery of legal services to student outcomes is complicated by data privacy issues as well as time horizons, with some cases remaining open long after a student has graduated. In addition, as the case study suggests, the potential benefits of integrating legal services onto a school campus go far beyond typical educational outcomes. In cases of direct representation, the services can 
change the course of a student's life, allowing them to stay in the country, secure benefits, gain employment, vote, and more. In addition to these transformative outcomes for a small group of individuals, the clinic also aims to empower the community and develop collective agency to make change-outcomes that are challenging to measure. Future research on this topic might benefit from the growing body of research on assessing students' competencies through portfolios and authentic performance tasks such as presenting and defending findings from a research project or a work-based internship experience (Maier et al., 2020; Marion \& Leather, 2015). For example, immigrant students who have opportunities to interact with community lawyers and/or the legal system may demonstrate their learning in a portfolio that documents the challenges they have had to navigate and what they have learned about American culture and the process of incorporation (Patel, 2013).

Additional research can also capture the experiences of clients-students and families-who received legal services after being referred by school staff. However, as stated above, entry into these cases requires care and deep trust. Working with lawyers is critical in ensuring ethical recruitment and methodologies. Scholars have called for schools to partner with legal service providers to address legal status issues (Lopez, 2021). For educational leaders that may want or need to establish supports for legal efforts related to immigration issues, assessing if an on-site legal clinic is the best route or if other options exist to partner with a local legal organization are available is important. Perhaps after gauging the extent of established supports or the scale of immigration issues present, a valuable partnership with legal professionals to address these issues may be beneficial. Ultimately, prioritizing a deep understanding of the experiences and needs of immigrant students and families in the community is critical in undertaking this work.

\section{Conclusion}

Despite the challenges and sensitivities in addressing immigration issues, students and families can benefit from the support of educators. The division and discord caused by anti-immigrant policies and rhetoric necessitates ethical and humane responses from educators (Rogers et al, 2017). As demonstrated in this study, this work is long-term, contextual, and difficult. School and community partnerships represent a vital source, yet often untapped source, for tackling immigration issues across K-12 settings, helping to extend reach in services and ensuring accurate information is shared with community members. 


\section{Appendix 1}

\section{Sample survey questions (selected)}

Demographics.

1. What is your role at the school?

a. Elementary School Teacher

b. Middle and High School Teacher

c. Administrator

d. Support Staff

e. Counselor

2. How long have you worked at the school?

a. Less than 5 years

b. 5 years or more

\section{Staff Knowledge}

3. How often do you talk with individuals from the following groups at the school about immigration-related legal issues or concerns? (on a 5-point likert scale from "never" to "very often"
a. Students
b. Teachers
c. Support Staff
d. Administrators
e. Counselors
f. Parents
g. Community members

Staff Connection

4. Have you referred anyone to the clinic?

a. Yes

b. No

a. How many referrals have you made?

i. One referral 
ii. Two to five referrals

iii. More than five referrals

b. Who did you connect or refer? Check all that apply.

i. A student

ii. A parent

iii. A community member

iv. Other:

c. If no, why or why not? Check all that apply.

i. I have not had an opportunity to connect/refer someone to the clinic.

ii. I don't know the process for connecting/referring people to the clinic.

iii. I feel uncomfortable talking about legal issues at the school.

iv. Other:

Clinic Services

5. To what extent do you feel informed about the clinic's activities and services?

a. Well-informed

b. Informed

c. Somewhat Informed

d. Not informed

As a follow-up to this survey, we invite you to volunteer to participate in a 45 to 60 -min interview about the clinic or receive more information about the clinic. You will receive a $\$ 25$ gift card if you are selected to be interviewed. Please click here to be redirected to another form to decline or accept this invitation. Thank you!

\section{Appendix 2}

\section{Sample interview questions (selected)}

Demographics.

1. Tell me about your role at the school.

2. How long have you worked at the school?

History/School Context. 
1. Immigration and legal status issues tend to generate a lot of attention in the media. However, these issues are often not connected to the way it impacts a child's education. Tell me about the events in and out of school that helped shape the creation of the clinic.

2. What do you think should be the responsibility of educators and schools to address immigration and documentation issues?

3. What is your perception of the school's views on immigrants?

\section{School Connection.}

1. In addition to the legal clinic, what other efforts is the school undertaking to support immigrant families?

\section{Immigrant Family Legal Clinic.}

1. What are your thoughts on having an immigrant family legal clinic on campus?

2. Have you connected/referred anyone to the clinic?

3. What is your understanding of the services the clinic provides?

4. What is something you have learned about immigration and legal status by having the clinic on campus? [This can include something as simple as learning about the need]

5. What are the challenges in integrating the clinic on campus? For example, making it part of the school community.

6. What are the benefits of having an immigration clinic on campus?

Funding This research was supported in part by a philanthropic gift to UCLA to create, support, and study the Immigrant Family Legal Clinic.

\section{Declarations}

Conflict of interest We have no known conflict of interest to disclose.

\section{References}

Abrego, L. (2020). Research as accompaniment: Reflections on objectivity, ethics, and emotions. Retrieved from https://escholarship.org/content/qt34v2g837/qt34v2g837.pdf

Abrego, L. J. (2006). “I can't go to college because I don't have papers”: Incorporation patterns of Latino undocumented youth. Latino Studies, 4(3), 212-231.

Abrego, L. J., \& Gonzales, R. G. (2010). Blocked paths, uncertain futures: The postsecondary education and labor market prospects of undocumented Latino youth. Journal of Education for Students Placed at Risk, 15(1-2), 144-157.

Amuedo-Dorantes, C., \& Antman, F. (2016). Can authorization reduce poverty among undocumented immigrants? Evidence from the deferred action for childhood arrivals Program. Economic Letters, $147,1-4$. 
Bhabha, J. (2019). Children on the move in the twenty-first century: Developing a rights-based plan of action. In M. Suarez-Orozco (Ed.), Humanitarianism and mass migration: Confronting the world crisis (pp. 83-98). University of California Press.

Bliss, L., Caley, S., \& Pettignano, R. (2011). An interdisciplinary collaborative approach to wellness: Adding lawyers to the healthcare team to provide integrated care for patients. The International Journal of Health and Wellness, 1(2), 130-139.

Carmean, M. (2012). Medical-legal partnerships: Unmet potential for legislative advocacy. Georgetown Journal on Poverty Law. \& Policy, 19, 499-514.

CARES Act, H.R.748, 116th Cong. (2020). https://www.congress.gov/bill/116th-congress/house-bill/748

Crawford, E. R. (2017). The ethic of community and incorporating undocumented immigrant concerns into ethical school leadership. Educational Administration Quarterly, 53(2), 147-179.

Crawford, E. R., Walker, D., \& Valle, F. (2018). Leading for change: School leader advocacy for undocumented immigrant students. Equity \& Excellence in Education, 51(1), 62-77.

Daniel, J., Quartz, K. H., \& Oakes, J. (2019). Teaching in community schools: Creating conditions for deeper learning. Review of Research in Education, 43(1), 453-480.

Duan, M. (2017). DACA Eligibility for mothers improves children's mental health. Stanford Medical News Center. Retrieved from https://med.stanford.edu/news/all-news/2017/09/dacaeligibility.

Ee, J., \& Gándara, P. (2020). The impact of immigration enforcement on the nation's schools. American Educational Research Journal, 57(2), 840-871.

Enriquez, L. (2011). Because we feel the pressure and we also feel the support: Examining the educational success of undocumented immigrant Latina/o students. Harvard Educational Review, 81(3), 476-500.

Fuller, S. M., Steward, W. T., Martinez, O., \& Arnold, E. A. (2020). Medical-Legal partnerships to support continuity of care for immigrants impacted by HIV: Lessons learned from california. Journal of Immigrant and Minority Health, 22(1), 212-215. https://doi.org/10.1007/s10903-019-00919-0

Gándara, P., \& Ee, J. (2021). Schools under siege: The impact of immigration enforcement on educational equity. Harvard Educational Press.

Gandhi, A., Slama, R., Park, S., Russo, P., Bzura, R., \& Williamson, S. (2016). Focusing on the whole student: Final report on the Massachusetts wraparound zones. American Institute for Research. Retrieved from https://www.air.org/sites/default/files/downloads/report/Wraparound-Zones-Massa chusetts-August-2015-rev.pdf.

Gonzales, R. G. (2016). Lives in limbo: Undocumented and coming of age in America. University of California Press.

Gonzales, R. G., Murillo, M. A., Lacomba, C., Brant, K., Franco, M. C., Lee, J., \& Vasudevan, D. S. (2017). Taking giant leaps forward. Center for American Progress. Retrieved from https://cdn.ameri canprogress.org/content/uploads/2017/06/21142115/DACAat5-brief2.pdf.

Gonzales, R. G. (2010). On the wrong side of the tracks: Understanding the effects of school structure and social capital in the educational pursuits of undocumented immigrant students. Peabody Journal of Education, 85(4), 469-485.

Gonzales, R. G. (2011). Learning to be illegal: Undocumented youth and shifting legal contexts in the transition to adulthood. American Sociological Review, 76(4), 602-619.

Gonzales, R. G., \& Chavez, L. R. (2012). "Awakening to a nightmare" abjectivity and illegality in the lives of undocumented 15-generation Latino immigrants in the United States. Current Anthropology, 53(3), 255-281.

Gonzales, R. G., Terriquez, V., \& Ruszczyk, S. P. (2014). Becoming DACAmented: Assessing the shortterm benefits of deferred action for childhood arrivals (DACA). American Behavioral Scientist, 58(14), 1852-1872.

Guzmán, B. L., Kouyoumdjian, C., Medrano, J. A., \& Bernal, I. (2018). Community cultural wealth and immigrant Latino parents. Journal of Latinos and Education, 20(1), 78-92. https://doi.org/10.1080/ 15348431.2018.1541801

Hainmueller, J., Lawrence, D., Martén, L., Black, B., Figueroa, L., Hotard, M., Jiménez, T. R., Mendoza, F., Rodriguez, M. I., Swartz, J. J., \& Laitin, D. D. (2017). Protecting unauthorized immigrant mothers improves their children's mental health. Science, 357, 1041.

Jordan, E. R. (2016). What we know and need to know about immigrant access to justice. South Carolina Law Review, 67, 295-327.

Lal. P., and Phillips, M. (2018). Discover the model: The critical need for school-based immigration legal services. California Law Review 106. Retrieved from https://papers.ssrn.com/sol3/papers.cfm?abstr act_id=3197721. 
League, A., Donato, K. M., Sheth, N., et al. (2021). A Systematic review of medical-legal partnerships serving immigrant communities in the United States. J Immigrant Minority Health, 23, 163-174. https://doi.org/10.1007/s10903-020-01088-1

López, R. M. (2021). The (Mis)Treatment and (Non)Education of Unaccompanied Immigrant Children in the United States. Boulder, CO: National Education Policy Center. Retrieved [April 14, 2021] from http://nepc.colorado.edu/publication/immigrant-children.

Maier, A., Daniel, J., \& Oakes, J.(2017). Community schools as an effective school improvement strategy: A review of the evidence. Palo Alto, CA: Learning Policy Institute. Retrieved from https://learn ingpolicyinstitute.org/product/community-schools-effective-school-improvement-report.

Maier, A., Adams, J., Burns, D., Kaul, M., Saunders, M., \& Thompson, C. (2020). Using performance assessments to support student learning: How district initiatives can make a difference. Learning Policy Institute.

Malone, H. J. (2020). Community schools: Bridging educational change through partnerships. Journal of Educational Change, 21(3), 487-497.

Mangual Figueroa, A. (2017). Speech or silence: Undocumented students' decisions to disclose or disguise their citizenship status in school. American Educational Research Journal, 54(3), 485-523.

Marion, S., \& Leather, P. (2015). Assessment and accountability to support meaningful learning. Education Policy Analysis Archives, 23(9), n9.

McLaughlin, M., Fehrer, K., \& Leos-Urbel, J. (2020). The way we do school: The making of Oakland's full-service community school district. Harvard Education Press.

Moore, K. A., Lantos, H., Harper, K., and Jones, R. (2017). Making the grade: A progress report and next steps for integrated student supports. Child Trends. Retrieved from https://www.childtrends.org/wpcontent/uploads/2017/12/ISS_ChildTrends_February2018.pdf.

Murillo, M. A., Quartz, K. H., Garcia, L. W., Liboon, C. A. (2021). Nested contexts of reception and K-12 schools: Addressing immigration status. AERA Open.

Murillo, M. A. (2017a). The art of the reveal: Undocumented high school students, institutional agents, and the disclosure of legal status. The High School Journal, 100(2), 88-108.

Murillo, M. A. (2021b). Undocumented and college-bound: A case study of the supports and barriers high school students encounter in accessing higher education. Urban Education, 56(6), 930-958.

National Academies of Sciences, Engineering, and Medicine. (2019). Monitoring educational equity. Washington, DC: The National Academies Press.

Nienhusser, H. K. (2013). Role of high schools in undocumented students' college choice. Education Policy Analysis Archives, 21(85), 1-32.

Oakes, J., Maier, A., \& Daniel, J. (2017). Community schools: An evidence-based strategy for equitable school improvement. National Education Policy Center. Retrieved from http://nepc.colorado.edu/ publication/equitable-community-schools

Oakes, J. (1992). Can tracking research inform practice? Technical, normative, and political considerations. Educational Researcher, 21(4), 12-21.

Oakes, J. (2005). Keeping track: How schools structure inequality. Yale University Press.

Oakes, J., Quartz, K. H., Gong, J., Guiton, G., \& Lipton, M. (1993). Creating middle schools: Technical, normative, and political considerations. The Elementary School Journal, 93(5), 461-480.

Oakes, J., Wells, A. S., Jones, M., \& Datnow, A. (1997). Detracking: The social construction of ability, cultural politics, and resistance to reform. Teachers College Record, 98(3), 482-510.

Olivas, M. A. (2020). Perchance to DREAM: A legal and political history of the dream act and DACA. New York University Press.

Patel, L. L. (2013). Youth held at the border: Immigration, education, and the politics of inclusion. Teachers College Press.

Perez, W. (2012). Americans by heart: Undocumented Latino students and the promise of higher education. Teachers College Press.

Peshkin, A. (1988). In search of subjectivity-one's own. Educational Researcher, 17(7), 17-21. https:// doi.org/10.3102/0013189X017007017

Quartz, K. H., Rabin, N., Murillo, M. A., \& Garcia, L W. (2021). Sanctuary schooling: A promising model for supporting students. In P. Gándara and J. Ee, Schools under siege: The impact of immigration enforcement on educational equity. Harvard Education Press.

Rodriguez, S., Monreal, T., \& Howard, J. (2020). "It's about hearing and understanding their stories": Teacher empathy and socio-political awareness toward newcomer undocumented students in the New Latino South. Journal of Latinos and Education, 19(2), 181-198. 
Rogers, J, Franke, M., Yun, J.E., Ishimoto, M., Diera, C., Geller, R., Berryman, A., \& Brenes, T. (2017). Teaching and learning in the age of Trump: Increasing stress and hostility in America's high schools. Los Angeles, CA: Institute for Democracy, Education, and Access. Retrieved from https:// idea.gseis.ucla.edu/publications/publications/files/teaching-and-learning-in-the-age-of-trump/at_ download/file.

Saldaña, J. (2016). The coding manual for qualitative researchers. SAGE.

Sanders, M. (2018). Crossing boundaries: A qualitative exploration of relational leadership in three fullservice community schools. Teachers College Record, 120(4), 1-36.

Scharf, I. (2006). Nourishing justice and the continuum: Implementing a blended model in an immigration law clinic. Clinical Law Review, 12(1), 243-282.

Sheets, B. (2013). Alabama's 2011 anti-immigrant law H.B. 56 still on books, gets new life under Trump. Alabama. Retrieved from https://www.al.com/news/birmingham/2017/03/hb_56_alabamas_2011_ anti-immig.html.

Suárez-Orozco, C., Yoshikawa, H., Teranishi, R., \& Suárez-Orozco, M. (2011). Growing up in the shadows: The developmental implications of unauthorized status. Harvard Educational Review, 81(3), 438-473.

United States Department of Education (2015). Supporting undocumented students: A guide for success in secondary and postsecondary settings. Washington D.C. Retrieved from https://www2.ed.gov/ about/overview/focus/supporting-undocumented-youth.pdf

USCIS. (2020). Refugees and asylum. U.S Citizenship and immigration services. Retrieved from https:// www.uscis.gov/humanitarian/refugees-and-asylum.

USCIS. (2020). Public charge. U.S Citizenship and immigration services. Retrieved from https://www. uscis.gov/green-card/green-card-processes-and-procedures/public-charge.

USCIS. (2021). Special immigrant juveniles. U.S Citizenship and immigration services. Retrieved from https://www.uscis.gov/working-in-the-united-states/permanent-workers/employment-based-immig ration-fourth-preference-eb-4/special-immigrant-juveniles.

Weintraub, D., Rodgers, M. A., Botcheva, L., Loeb, A., Knight, R., Ortega, K., \& Huffman, L. (2010). Pilot study of medical-legal partnership to address social and legal needs of patients. Journal of Health Care for the Poor and Underserved, 21(2), 157-168.

Wiley, K. E., Anyon, Y., Yang, J. L., Pauline, M. E., Rosch, A., Valladares, G., \& Pisciotta, L. (2018). Looking back, moving forward: Technical, normative, and political dimensions of school discipline. Educational Administration Quarterly, 54(2), 275-302.

Yin, R. K. (2018). Case study research and applications (6th ed.). SAGE.

Yoshikawa, H., Suárez-Orozco, C., \& Gonzales, R. (2016). Unauthorized status and youth development in the United States: Consensus statement of the society for research on adolescence. Journal of Research on Adolescence, 27, 4-19.

Publisher's Note Springer Nature remains neutral with regard to jurisdictional claims in published maps and institutional affiliations. 